\title{
EDUCATION AND TRAINING Raising concerns in the current NHS climate: a qualitative study exploring junior doctors' attitudes to training and teaching
}

\author{
Authors: Irene Gafson, ${ }^{A}$ Kanika Sharma ${ }^{B}$ and Ann Griffin ${ }^{C}$
}

\section{Background}

High profile cases continue to demonstrate failures to raise concerns with detrimental effects on patient safety. This research sought to establish what educational support junior doctors needed to effectively raise clinical and professional concerns.

\section{Study design}

A qualitative study with 16 participants taking part in three focus groups. The transcripts were thematically analysed.

Results

All the data could be coded into four themes: past experiences of teaching; suggested teaching; reporting mechanisms and educational challenges. Most participants were dissatisfied with the teaching they had received on raising concerns. Current systems were thought to be good for raising patient safety issues but not for concerns about professional behaviour of healthcare staff.

Conclusions

There is a need for improved education to tackle the way this is taught in postgraduate curricula. Frequent rotations and a lack of meaningful relationships left junior doctors feeling less invested in improving organisational culture. Junior doctors are apprehensive about raising concerns because of personal risk to their career trajectory.

KEYWORDS: Raising concerns, whistleblowing, postgraduate training, barriers, hidden curriculum

\section{Background}

Doctors have a professional duty to raise concerns. ${ }^{1}$ A noticeable failure of this professional duty was reported in the public inquiry investigating the Mid Staffordshire NHS Foundation Trust. This inquiry was prompted by a series of incidents that were not

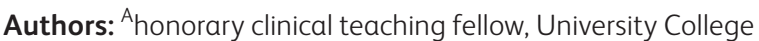
London Medical School, London, UK; ${ }^{B}$ honorary clinical teaching fellow, University College London Medical School, London, UK; ${ }^{C}$ director and lead for research, Research Department of Medical Education, University College London Medical School, London, UK appropriately identified, or acted on, between 2005 and 2009. Sir Robert Francis QC, who chaired the inquiry, subsequently published a report on the Freedom to speak up (FTSU) review which urged that 'every member of staff should receive training in their organisation's approach to raising concerns and in receiving and acting on them'. ${ }^{2}$ Senior advocates suggested that the review would trigger a 'cultural turning point' within the NHS for raising concerns. ${ }^{3}$ The barriers to raising concerns are considered to relate to organisational 'fear and hierarchy' which inhibits honest and open conversation. ${ }^{2,4}$ The Francis report highlighted the unique value of junior doctors with respect to raising concerns as the "eyes and ears in the hospital setting. 5

\section{Aim}

Four years have passed since the publication of the FTSU report; are the messages regarding change in culture and training in raising concerns now common practice? This qualitative exploration of junior doctors' experiences of teaching and training regarding raising concerns aimed to understand how effective current education is and to explore what educational interventions may support training junior doctors to raise concerns.

\section{Literature and policy review}

There are several national online learning resources for raising concerns; all freely accessible to doctors. ${ }^{6-8}$ Despite these resources, the most recent General Medical Council (GMC) trainee survey in 2018 had a chapter dedicated to reporting and acting on concerns. ${ }^{9}$ While $5.8 \%$ of respondents stated that they had been a victim of or witnessed bullying and undermining, only $6.4 \%$ of them chose to report it. Exploration of the facilitators and barriers to raising concerns is well researched. ${ }^{10-13}$ The most common barriers described in literature are now explicitly cited by the GMC in their raising concerns guidance:

Fear that nothing will be done; cause problems for colleagues, have a negative effect on working relationships; have a negative effect on your career; or result in a complaint about you. ${ }^{1}$

Studies exploring junior doctor attitudes to raising concerns repeatedly highlight that improving engagement in raising concerns required leadership and education. ${ }^{14,15}$ While education is cited as an important step towards improving reporting behaviour, few studies explicitly describe what this might involve. 
Rates of raising concerns are considered a key indicator of the overall quality of care offered by an organisation. ${ }^{16}$ In light of the fact that junior doctors are considered to be low reporters nationally, Hotton et al sought to improve rates of reporting through an 'incident reporting week'. ${ }^{17}$ Rates of raising concerns subsequently increased from two reports to 15 per month by junior doctors. They found that using clinical themes that were relevant to junior doctors and a dedicated reporting period was beneficial.

A similar project was carried out in the community paediatric setting to improve rates of raising concerns. In this instance, leaflets and posters were introduced to counter the barriers to reporting that staff had declared in questionnaires. ${ }^{18}$ While reporting trends improved after intervention, the study period was very short.

One of the critical challenges of teaching raising concerns is 'countering the hidden curriculum.' ${ }^{19}$ The 'hidden curriculum' is believed to 'achieve the enculturation of students as they develop into both practitioners and members of the medical profession'. ${ }^{20}$ This socialisation occurs in clinical environments outside of formal learning and can change the behaviour and attitudes of doctors, from open minded behaviours to close minded behaviours. ${ }^{21}$ In view of this, it is believed that formal educational reforms can often have low impact on reversing the 'sticky' change as experiences on the shop floor are so powerful. ${ }^{22}$

\section{Methods}

\section{Study design}

Qualitative and interpretive research was deployed to explore junior doctor attitudes. Interpretative phenomenological analysis (IPA) was used to explore how personal experiences have shaped beliefs and to reveal insights into attitudes.

Focus groups were chosen to gather data as they encourage participation from those reluctant to be interviewed one-to-one or from people who feel they have nothing to contribute. ${ }^{23}$

\section{Participants and recruitment}

Sixteen participants attended three focus groups. Participants were recruited by trust-wide email and face-to-face recruitment at departmental teaching. There was a mixture of junior doctor grades and specialties in each of the focus groups (see Table 1).

\section{Data gathering}

The focus groups were audio recorded and professionally transcribed. Observations were also carried out during the focus groups to advance the data analysis and assess levels of consensus.

A simple focus group question schedule was designed that directly mirrored the research question and sub-questions (see Fig 1). To maximise on the opportunities for participants to bounce ideas off each other, the questions were kept simple and conversational. Data saturation was reached during the third focus group with a definite sense that no new information was being gathered. ${ }^{24}$

\section{Ethics}

Participation was entirely voluntary and each participant was sent a participant information sheet and a participant consent
Table 1. Participant grade and specialty by focus

group

\begin{tabular}{|c|c|c|}
\hline Focus Group 1 & Focus Group 2 & Focus Group 3 \\
\hline $\begin{array}{l}\text { Obstetrics and } \\
\text { gynaecology registrar }\end{array}$ & $\begin{array}{l}\text { Anaesthetic } \\
\text { registrar }\end{array}$ & $\begin{array}{l}\text { Obstetrics and } \\
\text { gynaecology } \\
\text { registrar }\end{array}$ \\
\hline Anaesthetic registrar & Foundation Year 2 & $\begin{array}{l}\text { General practice } \\
\text { trainee }\end{array}$ \\
\hline $\begin{array}{l}\text { Obstetrics and } \\
\text { gynaecology senior } \\
\text { house officer }\end{array}$ & $\begin{array}{l}\text { Obstetrics and } \\
\text { gynaecology senior } \\
\text { house officer }\end{array}$ & $\begin{array}{l}\text { Anaesthetic senior } \\
\text { house officer }\end{array}$ \\
\hline $\begin{array}{l}\text { General practice } \\
\text { trainee }\end{array}$ & $\begin{array}{l}\text { Trust grade senior } \\
\text { house officer }\end{array}$ & Paediatric registrar \\
\hline $\begin{array}{l}\text { General practice } \\
\text { trainee }\end{array}$ & Unable to attend & $\begin{array}{l}\text { Anaesthetic senior } \\
\text { house officer }\end{array}$ \\
\hline $\begin{array}{l}\text { Obstetrics and } \\
\text { gynaecology senior } \\
\text { house officer }\end{array}$ & Unable to attend & $\begin{array}{l}\text { General surgical } \\
\text { registrar }\end{array}$ \\
\hline
\end{tabular}

form upon recruitment to the study. Ethics approval was sought from the University College London ethics committee via their low risk project ethics application form and approval granted (ethics approval reference: 12437/001).

\section{Analysis}

Immersion in the transcribed dataset allowed for thematic analysis to be carried out. For the purposes of this research, a 'theme' was considered something important and related to the research question that represented some 'level of patterned response within the data set.'. ${ }^{25}$ The themes were identified using an inductive approach. There was no pre-conceived coding

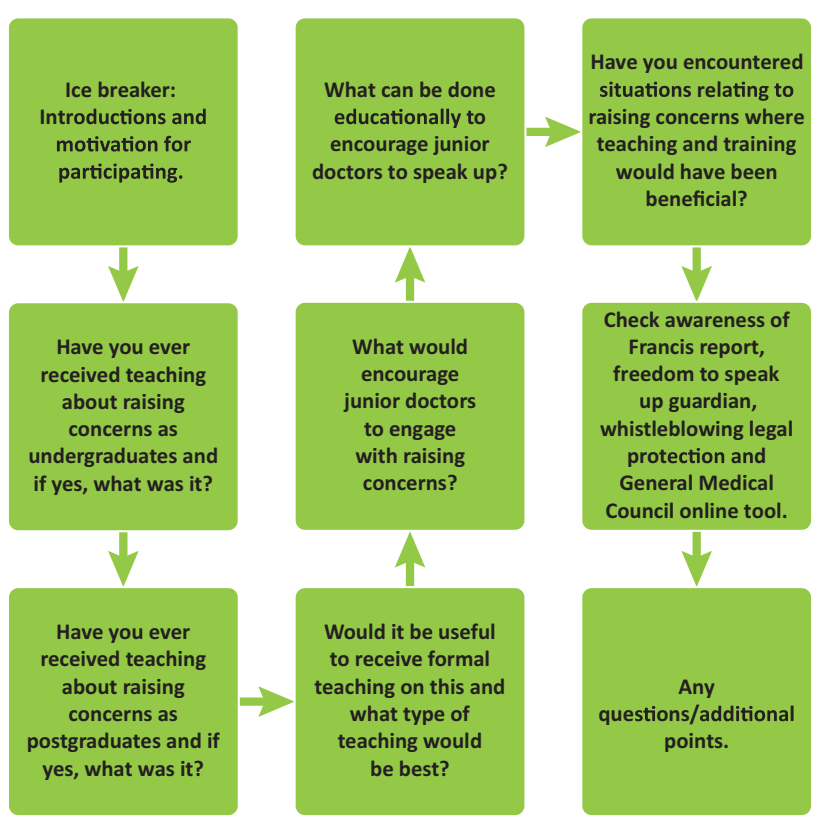

Fig 1. Focus group question schedule. 


\begin{tabular}{|c|c|}
\hline Themes & Sub-themes \\
\hline $\begin{array}{l}\text { Past experiences } \\
\text { of teaching }\end{array}$ & - undergraduate, postgraduate \\
\hline $\begin{array}{l}\text { Suggested } \\
\text { teaching }\end{array}$ & $\begin{array}{l}\text { - desire, timing, modality, content, } \\
\text { specifics }\end{array}$ \\
\hline $\begin{array}{l}\text { Reporting } \\
\text { mechanisms }\end{array}$ & $\begin{array}{l}\text { Datix reporting, other channels } \\
\text { for reporting concerns }\end{array}$ \\
\hline $\begin{array}{l}\text { Educational } \\
\text { barriers }\end{array}$ & $\begin{array}{l}\text { personal barriers, organisational } \\
\text { barriers, hierarchy }\end{array}$ \\
\hline
\end{tabular}

Fig 2. Pictorial representation of themes.

framework and there was an avoidance of trying to fit to the researchers' preconceptions. ${ }^{25}$

Two of the researchers coded the entire data set independently to improve the credibility of the coding. ${ }^{26}$ Both researchers then agreed the coding framework which contained four over-arching themes and several sub-themes (see Fig 2).

Once the framework was agreed, the entire dataset was coded using Nvivo software into these four overarching themes. ${ }^{27}$ An inter-coder reliability score was calculated using the software and the average percentage agreement was high (86\%).

\section{Results}

\section{Demographics}

There were four male and 12 female participants. Ten participants were in their earlier stages of junior doctor training (first 4 years) and six were more experienced. Individual participants were anonymised in the process of transcription and each was given a code.

The results are presented by theme using illustrative quotations from the participants. The participant's unique code is provided in brackets after any direct quote. 'FG' describes which focus group they participated in and ' $P$ ' is their participant number within that group. Table 2 provides more detailed examples of the quotations by participants to illustrate the discussion of the themes.

\section{Theme 1 - Past experiences of teaching}

Most participants received teaching on raising concerns at postgraduate level in induction and mandatory training, a minority were taught as undergraduates.

Several participants had formal raising concerns training delivered by external bodies, eg GMC, but highlighted how these sessions 'don't acknowledge the local complexities' (FG2P3).

Mandatory training and induction was perceived negatively, e-learning platforms failed to address the context and complexities around raising concerns and training was regarded as an organisational tick box.

\section{Theme 2 - Suggested teaching}

Some participants felt induction was an appropriate time as it 'fostered the right culture' from the start of the job. Others felt that the content would get lost amid other training and was impersonal. Participants were in favour of small group teaching as opposed to large group lectures. A general recurring sentiment was the need for a multidisciplinary team (MDT) approach to teaching about raising concerns.

Specific content requests included updates on the legal protection for a whistleblower or training in delivering negative feedback.

Many felt that use of 'real' examples (especially those with positive outcomes) could help to highlight what people should be flagging up.

\section{Theme 3 - Reporting mechanisms}

Many participants had direct experience in raising concerns about patient safety through the Datix system. The majority view was that this system was not suited to reporting concerns related to professionalism.

Outside of the Datix reporting system, there was uncertainty about other channels for raising concerns.

Most of the participants voiced the need for named people to approach when raising a concern, but there was no consensus about whether the individual should be within or external to their own department. Only one participant knew what a FTSU guardian was and participants strongly felt that this person should be more visible.

\section{Theme 4 - Educational challenges}

\section{Personal barriers}

For nearly all the participants, the personal risk was a major obstacle to raising concerns, and anonymity was a fear for all. Participants felt strongly about the need for "protecting themselves' through anonymous reporting (FG1P1).

The 'nomadic' nature of junior doctors' training with frequent changes in employment appeared to have a significant influence on most participants. Most did not really feel to be 'a part' of the hospital or feel a sense of duty to improve it.

\section{Organisational and current climate barriers}

To achieve the necessary cultural shift in raising concerns, many felt that role modelling by seniors and examples of good practice within an organisation were needed.

A commonly cited barrier to raising concerns across all three focus groups was lack of visible action from senior doctors and hospital management to concerns raised. There was little belief that this culture could change in this current generation.

While participants were not adverse to having formal teaching on raising concerns (especially as an MDT, see Theme 1), more senior participants did not think teaching would be sufficient to address the culture change needed.

\section{Hierarchy}

The issues of hierarchy within the medical profession were repeatedly mentioned in the focus groups and compared with the other healthcare professionals.

Medical hierarchies suppressed voicing concerns and that, with a perceived sense of apathy from seniors, curtailed concerns.

An example of a flat hierarchy was described in paediatrics and the positive experience associated with this in being able to raise 
Table 2. Themes with illustrative quotations

\begin{tabular}{|c|c|c|}
\hline Theme & Sub-theme & Quotation \\
\hline \multirow[t]{4}{*}{$\begin{array}{l}\text { Past } \\
\text { experience } \\
\text { of teaching }\end{array}$} & Undergraduate & $\begin{array}{l}\text { We had three afternoons... a pilot coming in to do fairly structured human practice training, which } \\
\text { obviously included raising concerns... for example, medical student being the one that notices you're } \\
\text { cutting off the wrong leg. FG1P1. }\end{array}$ \\
\hline & Postgraduate & It comes in that massive induction day where you do lose interest after the first hour. FG2P1. \\
\hline & & $\begin{array}{l}\text { We had a session when we were F2s I think from the GMC and it was talking about, you know, these } \\
\text { formal mechanisms...but the problem they don't acknowledge the complexities and how difficult it is } \\
\text { to actually raise a concern within the team that you're working in. FG2P3. }\end{array}$ \\
\hline & & $\begin{array}{l}\text { I think often the scenarios aren't nuanced enough. So the reality of when you're faced with this } \\
\text { scenario is it's not someone has done these bad things and therefore you follow these steps. FG2P3. }\end{array}$ \\
\hline \multirow[t]{8}{*}{$\begin{array}{l}\text { Suggested } \\
\text { teaching }\end{array}$} & Desire & $\begin{array}{l}\text { I think if a consultant sat down with you or at the beginning of your training ... and said in this trust } \\
\text { we have been trained how to raise concerns. I am the lead for raising concerns in our department. This } \\
\text { is how you would raise it. These are the people who you could go to. These are the kind of things the } \\
\text { raising concern consultant is looking for. FG1P2. }\end{array}$ \\
\hline & Timing & If you foster that culture in the beginning, we are a trust that supports this and endorses this. G3P4. \\
\hline & Modality & $\begin{array}{l}\text { If you're going to encourage everybody to raise concerns, it has to be trust-wide. Your background } \\
\text { doesn't matter. FG1P6. }\end{array}$ \\
\hline & Content & $\begin{array}{l}\text { It would be useful to ... do Balint ... where people bring the real-life situation and then discuss how } \\
\text { they managed it, would be useful and more systemic as well. FG1P4. }\end{array}$ \\
\hline & & $\begin{array}{l}\text { I think people learn more from positive examples and actually having some real stories of when you } \\
\text { have raised a concern in a way that has a positive outcome and these are the potential benefits of } \\
\text { doing so ... I think if you can bring that into it and really motivate people. FG2P3. }\end{array}$ \\
\hline & & $\begin{array}{l}\text { The introduction to the freedom to speak up guardian is a very useful thing and knowing that person } \\
\text { and having them speak to me even if it's only a 5-minute thing in a hospital-wide grand round or } \\
\text { something. FG2P3. }\end{array}$ \\
\hline & Specifics & $\begin{array}{l}\text { I'm just trying to think because obviously there's quite a gap between trainees and consultants. } \\
\text { So, I was wondering if you had a senior registrar who took on the role, who would liaise with the } \\
\text { consultants, but acts in the department as that role and led this teaching. FG1P2. }\end{array}$ \\
\hline & & $\begin{array}{l}\text { And I think, to drop the cliche of MDT, you kind of need everyone to be having the same culture ... So, } \\
\text { the training probably needs to, probably, focus on everyone at the same time in the same way. FG3P4. }\end{array}$ \\
\hline \multirow[t]{4}{*}{$\begin{array}{l}\text { Reporting } \\
\text { mechanisms }\end{array}$} & Datix reporting & $\begin{array}{l}\text { I think what it's meant to be used for sometimes are things like if you've arrived on a shift and it's understaffed. } \\
\text { But I mean it's just such a joke... Sorry, give me } 20 \text { minutes while I fill in one of these forms. FG1P5. }\end{array}$ \\
\hline & $\begin{array}{l}\text { Other channels } \\
\text { for reporting }\end{array}$ & $\begin{array}{l}\text { So if there is a patient safety issue and it's black and white then I definitely would, and I have many } \\
\text { times ... But it's when it's much greyer and it's those interpersonal things that it's actually very } \\
\text { difficult to do it. FG2P3. }\end{array}$ \\
\hline & & $\begin{array}{l}\text { We all said we must report this person ... but by the end of the shift ... everyone was completely fed } \\
\text { up, but no one really knew who to contact. FG3P2. }\end{array}$ \\
\hline & & $\begin{array}{l}\text { Perhaps if you have a named person that you would go to in your department ... Who would, maybe, } \\
\text { much better trained in dealing with these things, could then decide is this something that needs to be } \\
\text { formally escalated? FG3P5. }\end{array}$ \\
\hline \multirow[t]{5}{*}{$\begin{array}{l}\text { Educational } \\
\text { barriers }\end{array}$} & $\begin{array}{l}\text { Personal } \\
\text { barriers }\end{array}$ & $\begin{array}{l}\text { You also need to feel safe ... that you're not going to be persecuted, victimised, something bad is } \\
\text { going to happen to you as a result of raising a concern ... it might impact on your training and where } \\
\text { you go for your next jobs and things like that. FG3P4. }\end{array}$ \\
\hline & & $\begin{array}{l}\text { You need to know that it can be anonymous and managed anonymously. The problem is that in small } \\
\text { specialties maintaining that anonymity is quite difficult, isn't it? FG3P4. }\end{array}$ \\
\hline & $\begin{array}{l}\text { Organisational } \\
\text { barriers }\end{array}$ & $\begin{array}{l}\text { I almost feel like it's so endemic in the culture of consultants ... if you filter people in who are about to } \\
\text { become consultants it will like slowly change. FG1P2. }\end{array}$ \\
\hline & & $\begin{array}{l}\text { Sometimes trainees are bit apathetic about raising concerns because they're like, oh we'll have to live } \\
\text { with it for another six weeks. I'll just live with it and then it won't be my problem anymore. FG1P5. }\end{array}$ \\
\hline & & They don't have time to invest in our story because we move around for our training. FG3P4. \\
\hline
\end{tabular}


Table 2. (Continued)

\begin{tabular}{l} 
Theme Sub-theme $\quad \begin{array}{l}\text { Quotation } \\
\text { Hierarchy }\end{array}$ \\
$\begin{array}{l}\text { The attitude of people saying ... it's been like that for ages or they've been like that for years ... then } \\
\text { you feel like, you know, no one really cares. FG2P2. } \\
\text { It has to come from the top down. If it comes from seniors being educated who then filter that down } \\
\text { to us, that would work. FG1P2. } \\
\text { I have worked in one department where ... there's a flat hierarchy. You feel able to constantly question } \\
\text { things and talk, and you call the consultants on a first name, all those kinds of things that make it ... } \\
\text { easier. FG2P3. }\end{array}$ \\
\hline F2 = foundation year 2; GMC = General Medical Council; MDT = multidisciplinary team.
\end{tabular}

concerns. A suggestion was that teaching could be delivered by a junior doctor to help reduce hierarchy; there was unanimous agreement for this.

\section{Discussion}

\section{Principal findings}

Despite the fact that junior doctors had all received some form of training in raising concerns, they all still felt that they had a poor understanding of the process itself. When it came to concerns about individuals or professionalism, they felt they did not know who to approach or how to escalate. For those with personal experiences of trying to do this, they felt there were lots of invisible walls and a distinct lack of transparency.

\section{Implications for clinicians and policymakers}

There were distinct gaps in knowledge about recent changes relating to raising concerns, eg whistleblowing legal protection, pathways for escalation, role of the FTSU guardian etc. These gaps could be addressed by changes in the delivery of trust/ organisation raising concerns training, better guidance on legislation and signposting of who to discuss concerns with, with more emphasis on the FTSU guardian.

Focusing on raising concerns training outside of the induction process could prevent it being diluted by all the other mandatory training. Using small group teaching with case scenarios would seem to be a more effective way to convey the importance of raising concerns.

Mitigating against personal and organisational barriers and hierarchy could support juniors in raising concerns. Using examples of cases resulting in positive action could serve to improve attitudes to raising concerns. Sharing outcomes of concerns discussed at board level through hospital websites or raising concerns training would increase transparency and demonstrate what the trust valued.

The lack of a sense of organisational belonging was related to their relatively short placements in each employment and the difficulty of integrating with the community and becoming 'a part' of the organisation. This seemed to lead to a sense of apathy for improving the organisation and a lack of personal responsibility for raising concerns. A recent report, Being a junior doctor, by the Royal College of Physicians highlighted this as a major issue and described junior doctors feeling like 'migrant workers'. ${ }^{28}$ This report suggests that by improving induction and building stronger teams, junior doctors might have a stronger sense of belonging. In the context of raising concerns, this could be done by recruiting junior doctors to act as raising concerns champions and involving them in the delivery of any educational activity. This would help to make them feel an important part of the raising concerns process within the organisation.

Involving the wider MDT and encouraging healthcare practitioners to learn together, could be another way to build teams and belonging. Given the transient nature of junior doctor placements, interprofessional education (IPE) could allow for the reporting culture to improve and doctors to leave some sort of legacy with the more permanent members of staff.

Hierarchy was reported as a significant problem: we would argue that education has a role in changing this. Perhaps by involving all 'ranks' of medical staff in a teaching session, more senior team members might reveal their own insecurities and perspectives which could serve to flatten the hierarchy within a team. Having involvement of junior doctors in the teaching faculty could similarly serve to disrupt the typical hierarchical structure to this sort of teaching.

\section{Strengths and weaknesses of the study}

The literature review highlighted the lack of research exploring educational solutions to improving junior doctor engagement with raising concerns. This study clearly highlights that junior doctors have a desire and need to learn about this aspect of professionalism. It helped to highlight what formal elements of education might be beneficial from their point of view while illustrating the social educational challenges that educators need to be mindful of.

It is important to be aware that the research only explored the opinions of 16 junior doctors all currently working at one NHS trust. However, they had all worked at multiple different NHS trusts in their careers to date. The research was undertaken as an in depth exploratory piece of work and one cannot assume that the findings are representative of the opinions of junior doctors as a whole. Before embarking on any major educational initiatives, it would be sensible to expand this research and explore the attitudes of greater numbers of junior doctors in different regions.

\section{Conclusions}

The findings of this study highlight the educational need for junior doctors to be taught and trained about raising concerns. There are established and well-known mechanisms for reporting patient safety issues (ie clinical incident reporting) but unclear mechanisms for reporting concerns regarding professionalism. Although the FTSU guardian roles have been implemented, these are not yet well recognised among junior doctors. While the 
topic of how to raise concerns is often included at organisation induction, this may not be the best forum as it tends to get lost amid all the other mandatory training topics. A small group MDT teaching session using case studies and including a wide range of professionals would enable familiarisation and build confidence in how to raise concerns. This might also serve to break down barriers of hierarchy and allow for visible role modelling of the right behaviours in an open and honest forum.

\section{References}

1 General Medical Council. Raising and acting on concerns about patient safety. Manchester: GMC, 2012. www.gmc-uk.org/Raising_ and_acting_on_concerns_about_patient_safety_English_0617. pdf_48902813.pdf [Accessed 18 June 2018].

2 Francis R. Freedom to speak up - An independent review into creating an open and honest reporting culture in the NHS. National archives, 2015. https://freedomtospeakup.org.uk/wpcontent/uploads/2014/07/F2SU_web.pdf [Accessed on 18 June 2018].

3 Bennett D. Letter to foundation trust managers re. Freedom to speak up report. Monitor, 2015. www.gov.uk/government/ uploads/system/uploads/attachment_data/file/403205/Letter_ to_FT_managers_re_Francis_w-blowing.pdf [Accessed 18 ]une 2018].

4 Stephenson T. Blowing the whistle on unsafe care. Manchester: GMC, 2016. https://gmcuk.wordpress.com/2016/02/23/blowingthe-whistle-on-unsafe-care [Accessed 18 June 2018].

5 Francis R (chair). Report of the Mid Staffordshire NHS Foundation Trust public inquiry. Norwich: The Stationery Office, 2013. https:// assets.publishing.service.gov.uk/government/uploads/system/ uploads/attachment_data/file/279124/0947.pdf [Accessed 18 June 2018]

6 Health Education England. Raising and responding to concerns (whistleblowing). Leeds: HEE, 2018. https://hee.nhs.uk/our-work/ hospitals-primary-community-care/learning-be-safer/raisingresponding-concerns-whistleblowing [Accessed 18 June 2018].

7 NHS Employers. Draw the line. Raising concerns. Together we can make a difference. NHS, 2018. www.nhsemployers.org/ your-workforce/retain-and-improve/raising-concerns-at-workand-whistleblowing/information-for-employers/resources-andcampaign-materials\#1 [Accessed 18 June 2018].

8 General Medical Council. Raising concerns - decision tool. Manchester: GMC, 2018. www.gmc-uk.org/guidance/ethical_ guidance/decision_tool.asp [Accessed 18 June 2018].

9 General Medical Council. Training environments 2018: Key findings from the national training surveys. Manchester: GMC, 2018. www.gmc-uk.org/-/media/documents/training-environments-2018 pdf-76667101.pdf [Accessed 23 July 2019].

10 Attree M. Factors influencing nurses' decisions to raise concerns about care quality. J Nurs Manag 2007;15:392-402.

11 Evans SM, Berry JG, Smith BJ et al. Attitudes and barriers to incident reporting: a collaborative hospital study. BMJ Qual Saf 2006;15:39-43.
12 Jones A, Kelly DM. Whistle-blowing and workplace culture in older peoples' care: qualitative insights from the healthcare and social care workforce. Sociol Health Illn 2014;36:986-1002.

13 ICM, Care Quality Commission. Fear of raising concerns about care. A research report for the Care Quality Commission. CQC, 2013. www. cqc.org.uk/sites/default/files/documents/201304_fear_of_raising_ complaints_icm_care_research_report_final.pdf [Accessed 18 ]une 2018].

14 Hooper A. The handling by the General Medical Council of cases involving whistleblowers. Manchester: GMC, 2015. www.gmc-uk. org/Hooper_review_final_60267393.pdf [Accessed 18 June 2018]

15 Sujan M. An organisation without a memory: a qualitative study of hospital staff perceptions on reporting and organisational learning for patient safety. Reliability Engineering \& System Safety 2015;144:45-52.

16 Keogh B. Review into the quality of care and treatment provided by 14 hospital trusts in England: overview report. NHS, 2013. www. nhs.uk/NHSEngland/bruce-keogh-review/Documents/outcomes/ keogh-review-final-report.pdf [Accessed 18 June 2018].

17 Hotton E, Jordan L, Peden C. Improving incident reporting among junior doctors. BMJ Qual Improv Rep 2014;3:u202381.w2481.

18 Donnelly P. Improving reporting of critical incidents through education and involvement. BMJ Qual Improv Rep 2015:4:u206996.w3776.

19 Campbell AV, Chin J, Voo TC. Ethics and attitudes. In: Dent J, Harden R (eds), A practical guide for medical teachers, 4th edn. Elsevier, 2013:253-62.

20 Lempp H, Seale C. The hidden curriculum in undergraduate medical education: qualitative study of medical students' perceptions of teaching. BMJ 2004;329:770.

21 Mahood SC. Medical education. Beware the hidden curriculum. Can Fam Physician 2011;57:983-5.

22 Lingard L, Reznick R, Devito I, Espin S. Forming professional identities on the health care team: discursive constructions of the 'other' in the operating room. Med Educ 2002;36:728-34.

23 Kitzinger ]. Qualitative research. Introducing focus groups. BMJ 1995;311:299-302.

24 Stalmeijer RE, McNaughton N, Van Mook NKA. Using focus groups in medical education research: AMEE Guide No 91. Med Teach 2014:36:923-39.

25 Braun V, Clarke V. Using thematic analysis in psychology. Qualitative Research in Psychology 2006;3:77-101.

26 Sutton J, Austin Z. Qualitative research: data collection, analysis, and management. Can J Hosp Pharm 2015;68:226-31.

27 NVivo qualitative data analysis software. Version 10. QSR International, 2012.

28 Royal College of Physicians. Being a junior doctor. Experiences from the front line of the NHS. London: RCP, 2016. www.rcplondon.ac.uk/ guidelines-policy/being-junior-doctor [Accessed 18 June 2018].

Address for correspondence: Dr Irene Gafson, University College London Medical School, 74 Huntley Street, London WC1E 6BT, UK.

Email: irenegafson@doctors.org.uk 